\title{
Kinetics and Mechanism of Permanganate Oxidation of Inositol in Perchloric and Sulfuric Acids Solutions
}

\author{
Ahmed Fawzy ${ }^{1,2}$, *, Ishaq A. Zaafarany ${ }^{1}$, Hatem M. Altass ${ }^{1}$, Moataz H. Morad ${ }^{1}$, Jabir Alfahemi ${ }^{1}$ \\ ${ }^{1}$ Chemistry Department, Faculty of Applied Science, Umm Al-Qura University, Makkah, Saudi Arabia \\ ${ }^{2}$ Chemistry Department, Faculty of Science, Assiut University, Assiut, Egypt
}

\section{Email address:}

afsaad13@yahoo.com (A. Fawzy), iazaafarany@uqu.edu.sa (I. A. Zaafarany), hatem1401@hotmail.com (H. M. Altass), mhmorad@uqu.edu.sa (M. H. Morad),jhfahemi@uqu.edu.sa (J. Alfahemi)

${ }^{*}$ Corresponding author

\section{To cite this article:}

Ahmed Fawzy, Ishaq A. Zaafarany, Hatem M. Altass, Moataz H. Morad, Jabir Alfahemi. Kinetics and Mechanism of Permanganate Oxidation of Inositol in Perchloric and Sulfuric Acids Solutions. American Journal of Chemical Engineering.

Vol. 4, No. 5, 2016, pp. 98-104. doi: 10.11648/j.ajche.20160405.12

Received: August 29, 2016; Accepted: September 5, 2016; Published: September 24, 2016

\begin{abstract}
The kinetics of oxidation of inositol (INOS) by permanganate ion in both perchloric and sulfuric acids solutions was studied using a spectrophotometric technique at a constant ionic strength of $1.0 \mathrm{~mol} \mathrm{dm}^{-3}$ and at $25^{\circ} \mathrm{C}$. In both acids, the reactions showed a first order dependence with respect to [permanganate], whereas the orders with respect to [INOS] were found to be less than unity. The effect of acids concentrations suggests that the reactions were acid-catalyzed with fractionalsecond order kinetics in $\left[\mathrm{H}^{+}\right]$. Variation of either ionic strength or dielectric constant of the medium had no effect significantly on the oxidation rates. The reactions mechanism adequately describing the kinetic results was proposed. In both acids, the main oxidation products of inositol were identified by spectral and chemical tools as the corresponding monoketone derivative, namely inosose. Under comparable experimental conditions, the oxidation rate in sulfuric acid was approximately three times higher than that in perchloric acid. Regarding to the second order rate constants of these reactions, the activation parameters have been evaluated and discussed.
\end{abstract}

Keywords: Inositol, Oxidation, Acid, Permanganate, Kinetics, Mechanism

\section{Introduction}

Oxidation reactions are very important in organic synthesis. Among the important oxidizing agents, permanganate ion is widely used in the oxidation of many organic compounds in acidic, neutral and alkaline media [111]. The mechanism of oxidation reactions by permanganate ion is governed by $\mathrm{pH}$ of the medium [12]. During oxidation by permanganate, it is evident that the $\mathrm{Mn}$ (VII) in permanganate is reduced to various oxidation states in acidic, neutral and alkaline media. In acidic media, permanganate ion $\left(\mathrm{MnO}_{4}^{-}\right)$can exist in several different forms, $\mathrm{HMnO}_{4}$, $\mathrm{H}_{2} \mathrm{MnO}_{4}^{+}, \mathrm{HMnO}_{3}$, and $\mathrm{Mn}_{2} \mathrm{O}_{7}$. The oxidant has been assigned with an inner-sphere and an outer-sphere mechanism pathways in their redox reactions $[13,14]$. In general, reduction of permanganate ion in acidic media goes to either $\mathrm{Mn}^{\mathrm{IV}}$ or $\mathrm{Mn}^{\mathrm{II}}$, where the reduction potential of the
$\mathrm{Mn}^{\mathrm{VII}} / \mathrm{Mn}^{\mathrm{IV}}$ couple is $1.695 \mathrm{~V}$ and that of the $\mathrm{Mn}^{\mathrm{VII}} / \mathrm{Mn}^{\mathrm{II}}$ couple is $1.51 \mathrm{~V}$ [15].

Inositol is a water soluble six membered cyclic polyol, which is synthesized by both eukaryotes and prokaryote [16]. In humans most inositol is synthesized in the kidneys. Inositol and some of its mono and polyphosphates function as the basis for a number of signaling and secondary messenger molecules $[17,18]$. These are involved in insulin signal transduction, gene expression, breakdown of fats and reducing blood cholesterol [19]. Oxidation of inositol was studied by different oxidants like alkaline potassium periodate [20], alkaline diperiodatocuprate(III) [21], alkaline permanganate [22], $\mathrm{V}(\mathrm{V})$ in acid medium [23] and chromic acid [24]. A literature survey revealed that there is a lack of literature on the kinetics of oxidation of inositol by permanganate ion in acidicmedia. This observation prompted us to investigate the title reactions. The objectives of the present study are to check the reactivity of inositoltowards 
permanganate ion in different acidicmedia and to propose the oxidation reaction mechanism.

\section{Experimental}

\subsection{Materials}

The chemicals employed in the present work were of reagent grade and their solutions were prepared by dissolving the samples in bidistilled water. The stock solution of inositol was prepared by dissolving the sample (Merk) in bidistilled water. A fresh solution of potassium permanganate was prepared and standardized as reported earlier [25]. Sodium perchlorate and sodium sulfate were used to attain the required ionic strength in perchloric and sulfuric acids, respectively, and acetic acid to attain dielectric constant of the reactions media.

\subsection{Kinetic Measurements}

All kinetic measurements have been followed under pseudo-first order conditions where inositol was existed in a large excess over that of permanganate. The courses of the reactions were followed by monitoring the decay in the absorbance of permanganate as a function of timeat its absorption maximum $(\lambda=525 \mathrm{~nm})$, whereas the other constituents of the reaction mixtures did not absorb considerably at this wavelength. The absorption measurements were done in a temperature-controlled Shimadzu UV-VIS-NIR-3600 double-beam spectrophotometer.

First order plots of $\ln$ (absorbance) versus time were recorded to be straight lines up to at least $70 \%$ of the reactions completion. The observed first order rate constants $\left(k_{\text {obs }}\right)$ were calculated as the slopes of $\ln ($ Abs. $)$ versus time plots. The rate constants were the mean values of at least two kinetic measurements. The rate constants were reproducible to within $4 \%$. The orders of the reactions with respect to the reactants were determined from the slopes of the $\log k_{\text {obs }}$ versus $\log$ (Conc.) plots by varying the concentrations of inositol and acids, in turn, while keeping other conditions constant.

\section{Results}

\subsection{Stoichiometry and Product Identification}

Various sets of reaction mixtures containing various amounts of permanganate ion and inositol at constant $\left[\mathrm{H}^{+}\right]$, ionic strength, and temperature were allowed to react for $24 \mathrm{~h}$ for completion of the oxidation reactions. The unconsumed [permanganate] was determined spectrophotometrically at $525 \mathrm{~nm}$. The results indicated that two moles of permanganate are consumed by five mole of inositol to yield the oxidation products as shown in the following equation,

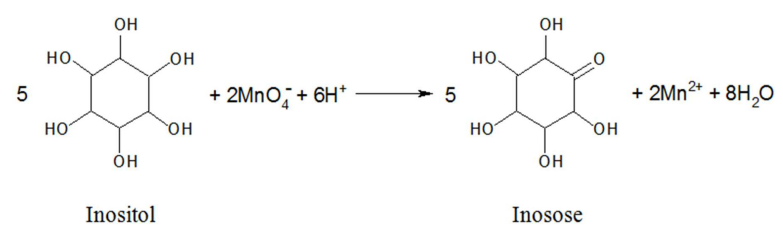

The above stoichiometric equation is consistent with the results of products identification which carried out by both spectral and chemical tools [26-28]. The oxidation product of inositol was identified as the corresponding monoketone derivative, namely inosose was also tested by addition of 2,4dinitrophenylhydrazine to the reaction mixture [26].

\subsection{Spectral Changes}

The spectral scans during the oxidation of inositol by permanganate ion in perchloric and sulfuric acid solutions are shown in Fig. 1 (a) and (b), respectively. It was shown that there are gradual disappearance of permanganate band at its absorption maximum $(\lambda=525 \mathrm{~nm})$ as a result of its reduction by inositol substrate.

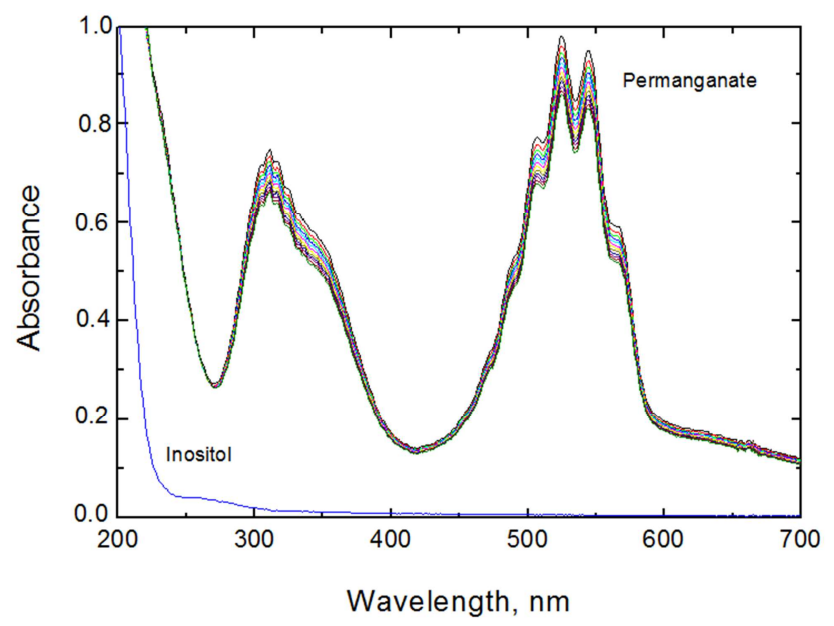

(a)

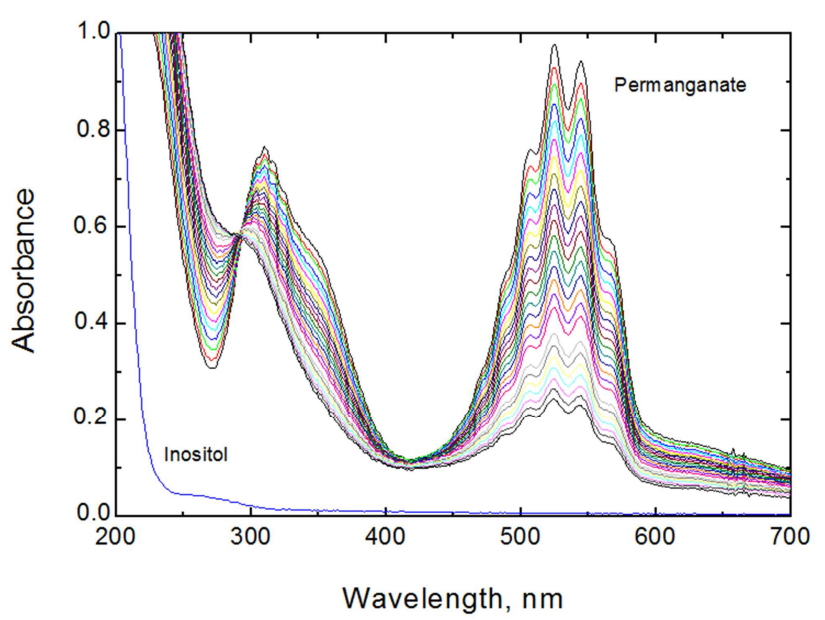

(b)

Figure 1. Spectral changes during the oxidation of inositol by permanganate ion in: (a) perchloric, and (b) sulfuric acid solutions. [INOS] $=1.0 \times 10^{-2}$, $\left[\mathrm{MnO}_{4}^{-}\right]=4.0 \times 10^{-4},\left[\mathrm{H}^{+}\right]=0.5$ and $I=1.0 \mathrm{~mol} \mathrm{dm}{ }^{-3}$ at $25^{\circ} \mathrm{C}$. Scanning time intervals $=1.0 \mathrm{~min}$. 


\subsection{Dependence of Reaction Rate on [MnO $\left.{ }_{4}^{-}\right]$}

The concentration of permanganate ion was varied in the range of $1.0-8.0 \times 10^{-4} \mathrm{~mol} \mathrm{dm}^{-3}$ while the rest of the reactant concentrations were kept constant. It has been found that, plots of $\ln ($ Abs.) versus time were linear up to about $70 \%$ of the reactions completion. Furthermore, the increase in the oxidant concentration did not changethe oxidation rates as listed in Table 1. These results indicate that the order of the reactions with respect to the oxidant is confirmedto be one.

\subsection{Dependence of Reaction Rate on [INOS]}

The observed first order rate constants were measured at various concentrations of inositol keeping others constant. In both perchloric and sulfuric acid solutions, plots of $k_{\text {obs }}$ versus [INOS] were found to be linear with positive intercepts on $k_{\text {obs }}$ axes as shown in Fig. 2 confirming the less than unit order dependences with respect to inositol concentration.

\subsection{Dependence of Reaction Rate on $\left[\mathrm{H}^{+}\right]$}

The influence of both perchloric and sulfuric acids on the rates was investigated by varying the hydrogen ion concentration in the range of $0.1-0.9 \mathrm{~mol} \mathrm{dm}^{-3}$, keeping all other reactants concentrations constant. The rate constants increased with increasing acid concentration (Table 1). Plots of $\log k_{\text {obs }}$ versus $\log \left[\mathrm{H}^{+}\right]$were also linear with slopes of 1.62 and 1.57 in both acids, respectively, Fig, 3, suggesting that the orders of reactions with respect to $\left[\mathrm{H}^{+}\right]$were fractional-second.

\subsection{Effect of Ionic Strength and Dielectric Constant}

The effect of ionic strength has been investigated by varying the concentration of $\mathrm{NaClO}_{4}$ in case of perchloric acid and $\mathrm{Na}_{2} \mathrm{SO}_{4}$ in case of sulfuric acid solutions in the reactions media at constant concentrations of permanganate, inositol and acids. It was found that variation in ionic strength did not affect the rates as observed from the data listed in Table 1. Furthermore, the effect of dielectric constant $(D)$ was also studied by varying the acetic acid water content in the reaction mixture with all other conditions being kept constant. The data clearly revealed that the rate constants did not significantly affected by the decrease in dielectric constant of the solvent mixture; i.e. increase in acetic acid content.

Table 1. Effect of variation of $\left[\mathrm{MnO}_{4}^{-}\right],[\mathrm{INOS}],\left[\mathrm{H}^{+}\right]$and I on the observed first order rate constants $\left(k_{o b s}\right)$ in the oxidation of inositol by permanganate ion in perchloric and sulfuric acids solutions at $25^{\circ} \mathrm{C}$.

\begin{tabular}{|c|c|c|c|c|c|}
\hline \multirow{2}{*}{$\begin{array}{l}\mathrm{10}^{4}\left[\mathrm{MnO}_{4}^{-}\right] \\
\left(\mathrm{mol} \mathrm{dm}^{-3}\right)\end{array}$} & \multirow{2}{*}{$\begin{array}{l}\mathbf{1 0}^{2}[\mathrm{INOS}] \\
\left(\mathbf{m o l} \mathbf{d m}^{-3}\right)\end{array}$} & \multirow{2}{*}{$\begin{array}{l}{\left[\mathrm{H}^{+}\right]} \\
\left(\mathbf{m o l ~ d m ^ { - 3 }}\right)\end{array}$} & \multirow{2}{*}{$\left.\begin{array}{l}I \\
(\mathrm{~mol} \mathrm{dm} \\
-3\end{array}\right)$} & \multicolumn{2}{|l|}{$10^{5} k_{\text {obs }}\left(\mathrm{s}^{-1}\right)$} \\
\hline & & & & Perchloric & Sulfuric \\
\hline 1.0 & 1.0 & 0.5 & 1.0 & 23.9 & 73.4 \\
\hline 2.0 & 1.0 & 0.5 & 1.0 & 24.5 & 74.1 \\
\hline 4.0 & 1.0 & 0.5 & 1.0 & 23.7 & 72.6 \\
\hline 6.0 & 1.0 & 0.5 & 1.0 & 25.6 & 69.8 \\
\hline 8.0 & 1.0 & 0.5 & 1.0 & 22.1 & 71.0 \\
\hline 4.0 & 0.2 & 0.5 & 1.0 & 8.7 & 21.5 \\
\hline 4.0 & 0.6 & 0.5 & 1.0 & 15.8 & 48.5 \\
\hline 4.0 & 1.0 & 0.5 & 1.0 & 23.7 & 72.6 \\
\hline 4.0 & 1.4 & 0.5 & 1.0 & 28.8 & 94.0 \\
\hline 4.0 & 1.8 & 0.5 & 1.0 & 35.5 & 115.1 \\
\hline 4.0 & 1.0 & 0.1 & 1.0 & 3.1 & 7.6 \\
\hline 4.0 & 1.0 & 0.3 & 1.0 & 12.8 & 37.2 \\
\hline 4.0 & 1.0 & 0.5 & 1.0 & 23.7 & 72.7 \\
\hline 4.0 & 1.0 & 0.7 & 1.0 & 39.3 & 99.8 \\
\hline 4.0 & 1.0 & 0.9 & 1.0 & 53.2 & 133.0 \\
\hline 4.0 & 1.0 & 0.5 & 1.0 & 23.7 & 72.7 \\
\hline 4.0 & 1.0 & 0.5 & 1.5 & 24.1 & 74.3 \\
\hline 4.0 & 1.0 & 0.5 & 2.0 & 22.0 & 71.8 \\
\hline 4.0 & 1.0 & 0.5 & 2.5 & 23.7 & 75.0 \\
\hline 4.0 & 1.0 & 0.5 & 3.0 & 25.2 & 73.7 \\
\hline
\end{tabular}

Experimental error $\pm 3 \%$ 


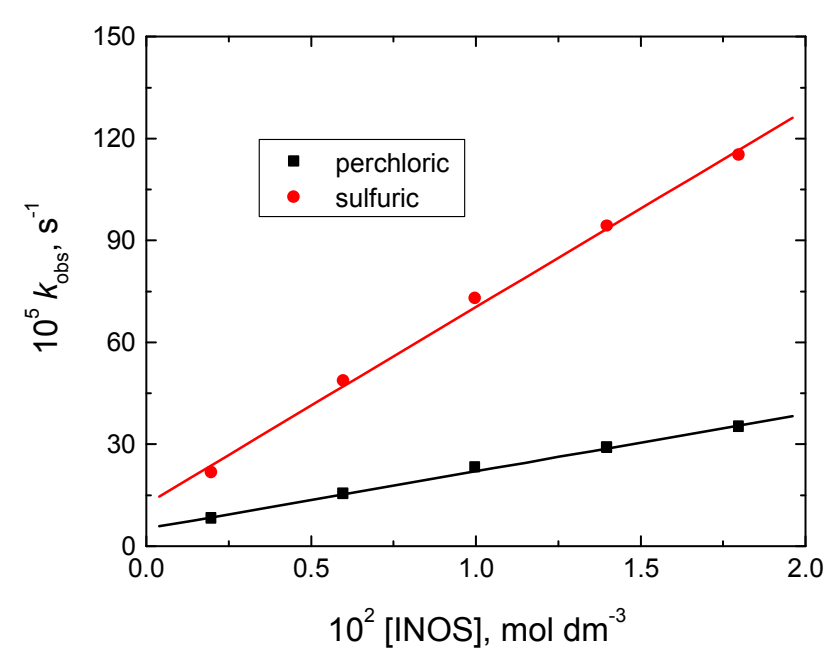

Figure 2. Plots of the observed first order rate constants $\left(k_{o b s}\right)$ versus [INOS] in the oxidation of inositol by permanganate ion in perchloric and sulfuric acids solutions. $\left[\mathrm{MnO}_{4}^{-}\right]=4.0 \times 10^{-4},\left[\mathrm{H}^{+}\right]=0.5$ and $I=1.0 \mathrm{~mol} \mathrm{dm}^{-3}$ at $25^{\circ} \mathrm{C}$.

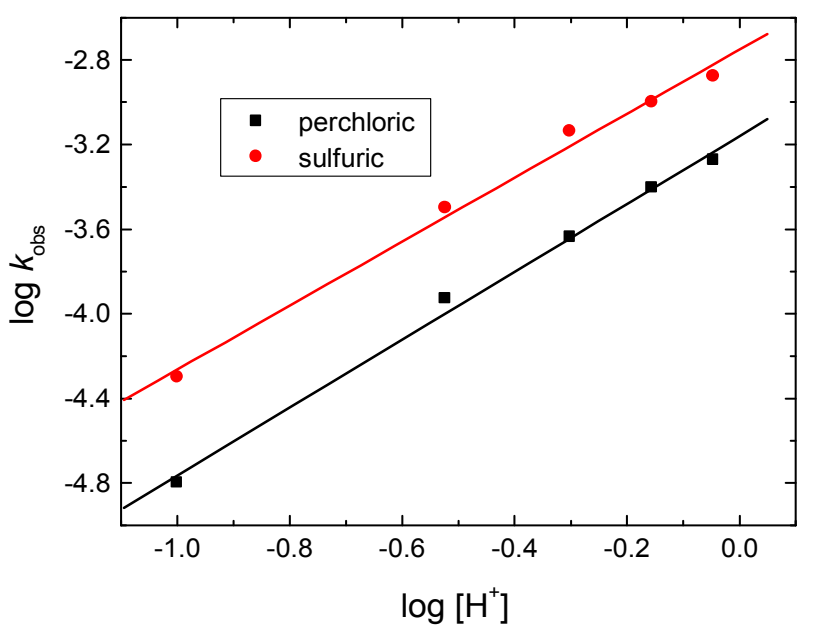

Figure 3. Plots of $\log k_{\text {obs }}$ versus $\log \left[\mathrm{H}^{+}\right]$in the oxidation of inositol by permanganate ion in perchloric and sulfuric acids solutions. $\left[\mathrm{MnO}_{4}^{-}\right]=4.0$ $\times 10^{-4},[I N O S]=1.0 \times 10^{-2}$ and $I=1.0 \mathrm{~mol} \mathrm{dm}^{-3}$ at $25^{\circ} \mathrm{C}$.

\subsection{Effect of Temperature}

The rates of the reactions were carried out at five different temperatures between 283 and $308 \mathrm{~K}$ at constant concentrations of the reactants and other conditions being constant. The results indicate that the rate constants increased with rise in temperature. The activation parameters of the second order rate constant $\left(k_{2}\right)$ are calculated using Eyring and Arrhenius plots and are listed in Table 2.

Table 2. Activation parameters of the second order rate constant $\left(k_{2}\right)$ in the oxidation of inositol by permanganate ion in perchloric and sulfuric acids solutions. $\left[\mathrm{MnO}_{4}^{-}\right]=4.0 \times 10^{-4}$, [INOS $]=1.0 \times 10^{-2},\left[\mathrm{H}^{+}\right]=0.5$ and $\mathrm{I}=1.0$ mol dm $m^{-3}$

\begin{tabular}{|c|c|c|c|c|}
\hline Acid & $\Delta S^{\ddagger} \mathbf{J} \mathrm{mol}^{-1} \mathbf{K}^{-1}$ & $\Delta H^{\ddagger} \mathrm{kJ} \mathrm{mol}^{-1}$ & $\Delta G^{f}{ }_{298}^{\prime} \mathbf{k J ~ m o l}^{-1}$ & $E_{\mathrm{a}}^{\neq}, \mathrm{kJ} \mathrm{mol}^{-1}$ \\
\hline Perchloric & -77.87 & 62.30 & 85.50 & 65.07 \\
\hline Sulfuric & -81.02 & 57.81 & 81.91 & 59.93 \\
\hline
\end{tabular}

\subsection{Polymerization Study}

To check the existence of free radicals in the reactions under investigations, the reactions mixtures were mixed with identified quantities of acrylonitrile and kept for 8 hours under nitrogen. On dilution with methanol, white precipitates were formed, indicating the participation of free radicals in the oxidation reactions. The blank experiments which were carried out with either permanganate or inositol with acrylonitrile did not induce polymerization under the same experimental conditions.

\section{Discussion}

It was reported [3-11] that most permanganate oxidation reactions proceed through intermediate complex formation between the oxidant and substrate. The investigated reactions between inositol and permanganate ion in both perchloric and sulfuric acids solutions have a stoichiometry of 5:2, INOS : $\mathrm{MnO}_{4}{ }^{-}$. The reactions exhibited a first order dependence with respect to $\left[\mathrm{MnO}_{4}^{-}\right]$and less than unit order dependences with respect to [INOS]. The reactions exhibited fractional-second order kinetics in $\left[\mathrm{H}^{+}\right]$suggesting protonation of both permanganate ion [29,30] and inositol in the first steps of the reactions(illustrated by steps (1) and (2) in Scheme 1) to form more reactive species of both reactants. On the other hand, the less than unit order dependences with respect to inositol concentration in both acids suggest formation of intermediate complexes (C) between the kinetically active species of inositol substrate and permanganate oxidant prior to the ratedetermining step. Complexes formation was also proved kinetically by the non-zero intercept of the plots of $1 / k_{\text {obs }}$ versus $1 /[$ INOS], Fig. 4, in favor of possible formation of a transient complex flanked by oxidant and substrate comparable with the well-known Michaelis-Menten mechanism for enzyme-substrate reactions [31]. The observed insignificant effect of either ionic strength or dielectric constant of the reactions media on the oxidation rates implies association of two neutral molecule or between a neutral molecule and an ion [32,33], i.e. between acid permanganate and protonated inositol.

Owing to the experimental results, a plausible reactions mechanism has been proposed which involves protonation of both permanganate ion and inositol in the first two steps followed by complexation of the protonated reactants prior to the rate-determining step. Such complex decomposes yielding a free radical intermediate derived from inositol substrate and manganate(VI) intermediate. The free radical is attacked by manganate(VI) to give the corresponding mono ketone (inosose) as the final oxidation product of inositol. In a further fast step the intermediate $\mathrm{Mn}(\mathrm{V})$, being very active and unstable in acidic medium, reacts with another inositol substrate to form also inosose product and an intermediate Mn(III) species. This step is followed by other fast steps including reactions of inositol with acid permanganate species to form again the final oxidation products and 
Mn(III) species. The last step is the attack of Mn(III) species on another inositol molecule to give the final oxidation

product and $\mathrm{Mn}(\mathrm{II})$ satisfying the obtained stoichiometry.

$\mathrm{MnO}_{4}^{-}+\mathrm{H}^{+} \stackrel{K_{1}}{\rightleftharpoons} \mathrm{HMnO}_{4}$<smiles>[Y4]C=C[CH+]C=C</smiles>

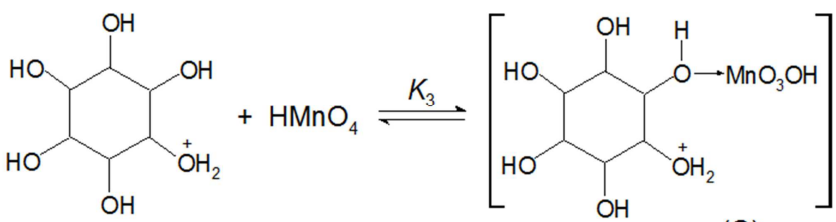

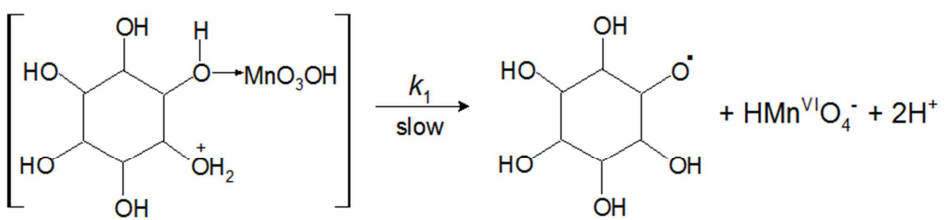

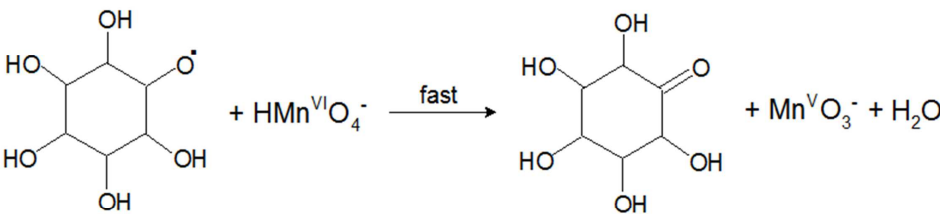<smiles>O=C1C(O)C(O)C(O)C(O)C1O</smiles><smiles>CO[C@H]1C(=O)C(O)C(O)C(O)C1O</smiles>

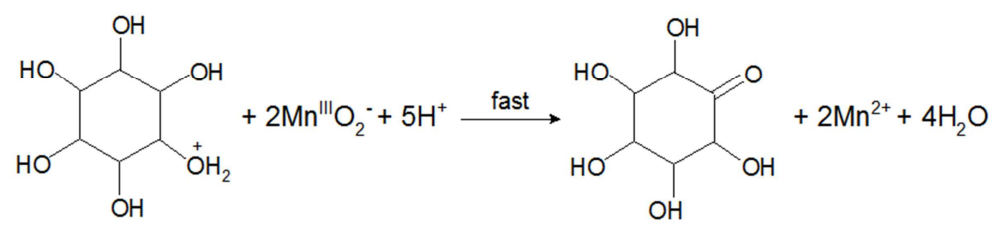

Scheme 1. Mechanism of oxidation of inositol by permanganate ion in acidic media.

Owing to the proposed mechanistic Scheme 1, the oxidation rate can be expressed by the following rate law:

$$
\text { Rate }=\frac{-d\left[\mathrm{MnO}_{4}^{-}\right]}{d t}=k_{1}[\mathrm{C}]
$$

The relationship between the oxidation rate and the oxidant, substrate and hydrogen ion concentrations is deduced (See Appendix A) to give the following equation:

$$
\text { Rate }=\frac{k_{1} K_{1} K_{2} K_{3}\left[\mathrm{MnO}_{4}^{-}\right][\mathrm{INOS}]\left[\mathrm{H}^{+}\right]^{2}}{1+K_{1}\left[\mathrm{H}^{+}\right]+K_{1} K_{2} K_{3}[\mathrm{INOS}]\left[\mathrm{H}^{+}\right]^{2}}
$$

Under pseudo-first order condition, the ratelaw can be expressed by Eq. (12),

$$
\text { Rate }=\frac{-d\left[\mathrm{MnO}_{4}^{-}\right]}{d t}=k_{\mathrm{obs}}\left[\mathrm{MnO}_{4}^{-}\right]
$$


Comparing Eqs. (11) and (12) and rearrangement, the following equation is obtained:

$$
\frac{1}{k_{o b s}}=\left(\frac{1+K_{1}\left[\mathrm{H}^{+}\right]}{k_{1} K_{1} K_{2} K_{3}\left[\mathrm{H}^{+}\right]^{2}}\right) \frac{1}{[\mathrm{INOS}]}+\frac{1}{k_{1}}
$$

According to Eq. (13), other conditions being constant, plots of $1 / k_{\text {obs }}$ versus $1 /\left[\right.$ INOS] at constant $\left[\mathrm{H}^{+}\right]$and $1 / k_{\text {obs }}$ versus $1 /\left[\mathrm{H}^{+}\right]^{2}$ at constant $[\mathrm{INOS}]$ should be linear with positive intercepts on the $1 / k_{\mathrm{obs}}$ axes and are indeed found to be so as shown in Figs. 4 and 5. The slopes and intercepts of such plots lead to calculate the values of $k_{1}, K_{1}$ and $K_{2}$.

The activation parameters listed in Table 2 may be interpreted as follows. The obtained large negative values of $\Delta S^{\ddagger}$ suggest compactness of the formed complexes [34]. Also, the obtained values of $\Delta S^{\neq}$are within the range of radical reactions. The positive values of both $\Delta H^{\ddagger}$ and $\Delta G^{\ddagger}$ confirm endothermic formation of the intermediate complexes and their non-spontaneities, respectively.

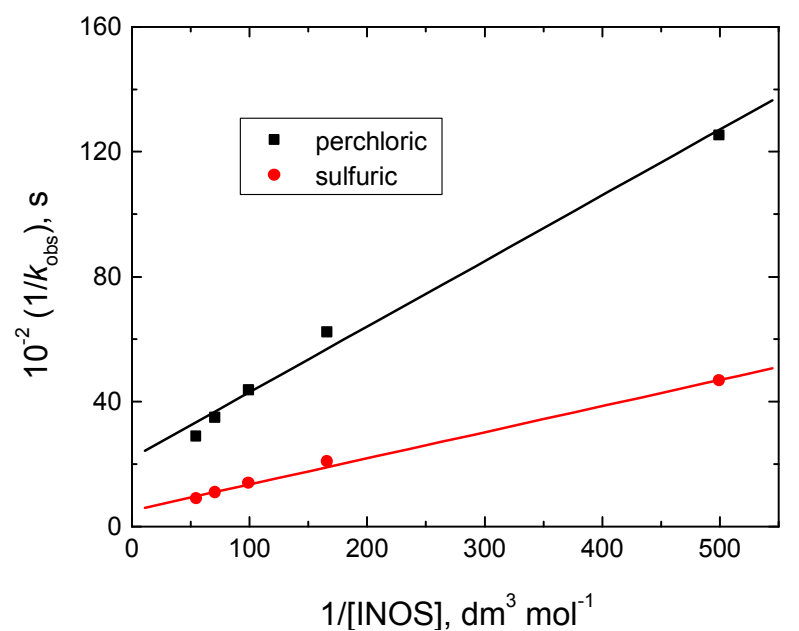

Figure 4. Plots of $1 / k_{\text {obs }}$ versus $1 /$ [INOS] in the oxidation of inositol by permanganate ion in perchloric and sulfuric acids solutions. $\left[\mathrm{MnO}_{4}^{-}\right]=4.0$ $x 10^{-4},\left[\mathrm{H}^{+}\right]=0.5$ and $\mathrm{I}=1.0 \mathrm{~mol} \mathrm{dm}{ }^{-3}$ at $25^{\circ} \mathrm{C}$.

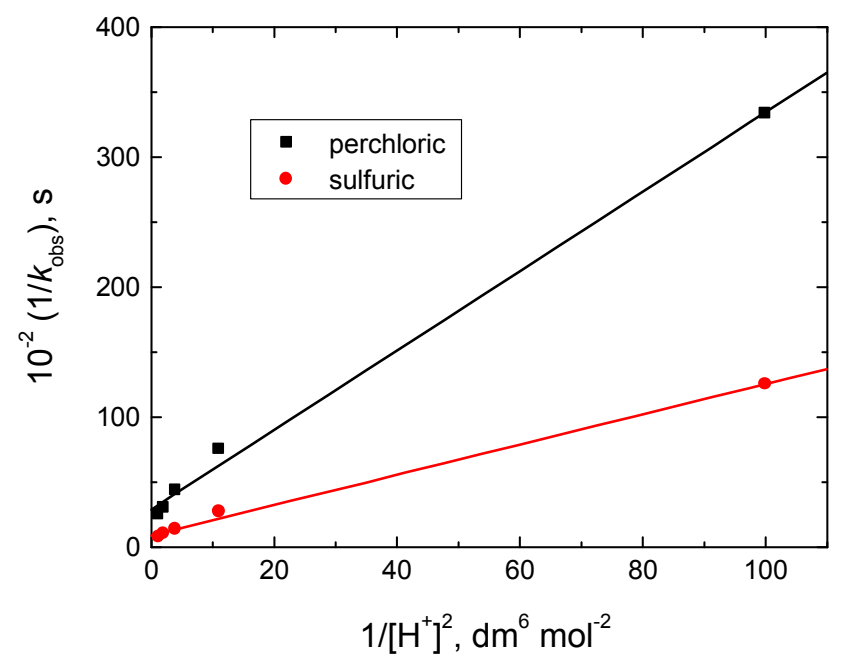

Figure 5. Plots of $1 / k_{\text {obs }}$ versus $1 /\left[H^{+}\right]^{2}$ in the oxidation of inositol by permanganate ion in perchloric and sulfuric acids solutions. $\left[\mathrm{MnO}_{4}{ }^{-}\right]=4.0$ $x 10^{-4}$, [INOS] $=1.0 \times 10^{-2}$ and $I=1.0 \mathrm{~mol} \mathrm{dm}^{-3}$ at $25^{\circ} \mathrm{C}$.

\section{Conclusions}

The kinetics of oxidation of inositol by permanganate ion in both perchloric and sulfuric acids solutions has been studied. The final oxidation product of inositol was identified in both cases as the corresponding monoketone, namely inosose. Under comparable experimental conditions, the oxidation rate in sulfuric acid was about three times higher than that in perchloric acid. The activation parameters have been evaluated and discussed.

\section{References}

[1] Stewart R (1965) Oxidation in Organic Chemistry, Part A (ed.) Wiberg KB, New York, Academic Press.

[2] Jose TP, Nandibewoor ST, Tuwar SM (2005) Mechanism of oxidation of L-histidine by heptavalent manganese in alkaline medium. E-J. Chem. 2: 75-85.

[3] Fawzy A, Ashour SS, Musleh MA, (2014) Base-catalyzed oxidation of L-asparagine by alkaline permanganate and the effect of alkali-metal ion catalysts: kinetics and mechanistic approach, React. Kinet. Mech. Catal. 111:443-460.

[4] Fawzy A, Shaaban MR (2014) Kinetic and mechanistic investigations on the oxidation of N'-heteroaryl unsymmetrical formamidines by permanganate in aqueous alkaline medium. Transition Met. Chem. 39: 379-386.

[5] Fawzy A, Zaafarany IA, Alfahemi J, Tirkistani FA (2015) Base-catalyzed oxidation of aminotriazole derivative by permanganate ion in aqueous alkaline medium: a kinetic study. Int. J. Inn. Res. Sci. Eng. Tech. 4: 6802-6814.

[6] Asghar BH, Fawzy A (2014) Kinetic, mechanistic, and spectroscopic studies of permanganate oxidation of azinylformamidines in acidic medium, with autocatalytic behavior of manganese(II). J. Saudi Chem. Soc., in press.

[7] Fawzy A, Ashour SS, Musleh MA (2014) Kinetics and mechanism of oxidation of L-histidine by permanganate ions in sulfuric acid medium. Int. J. Chem. Kinet. 46: 370-381.

[8] Ahmed GA, Fawzy A, Hassan RM (2007) Spectrophotometric evidence for the formation of short-lived hypomanganate $(\mathrm{V})$ and manganate(VI) transient species during the oxidation of $K$-carrageenan by alkaline permanganate. Carbohydr. Res. 342: 1382-1386.

[9] Zaafarany IA, Fawzy A, Ahmed GA, Ibrahim SA, Hassan RM, Takagi HD (2010) Further evidence for detection of short-lived transient hypomanganate(V) and manganate(VI) intermediatesduring oxidation of some sulfated polysaccharides by alkaline permanganate using conventional spectrophotometeric techniques. Carbohydr. Res. 345:15881593.

[10] Hassan RM, Fawzy A, Alarifi A, Ahmed GA, Zaafarany IA, Takagi HD (2011) Base-catalyzed oxidation of some sulfated macromolecules: kinetics and mechanism of formation of intermediate complexes of short-lived manganate (VI) and/or hypomanganate $(\mathrm{V})$ during oxidation of iota- and lambdacarrageenan polysaccharides by alkaline permanganate. J. Mol. Catal. A, 335:38-45. 
[11] Hassan RM, Dahy A, Ibrahim S, Zaafarany IA, Fawzy A (2012) Oxidation of some macromolecules. Kinetics and mechanism of oxidation of methyl cellulose polysaccharide by permanganate ion in acid perchlorate solutions. Ind. Eng. Chem. Res. 51:5424-5432.

[12] Gardner KA, Kuehnert LL, Mayer JM (1997) Hydrogen atom abstraction by permanganate: oxidations of arylalkanes in organic solvents. Inorg. Chem. 36: 2069-2078.

[13] Perez-Benito JF (2009) Permanganate oxidation of $\alpha$-amino acids: kinetic correlations for the nonautocatalytic and autocatalytic reaction pathways. J. Phys. Chem. 113:159825989.

[14] Babatunde OAA (2008) study of the kinetics and mechanism of oxidation L-ascorbic acid by permanganate ion in acidic medium. World J. Chem. 3:27-35.

[15] Day MC, Selbin J (1985) Theoretical Inorganic Chemistry, Reinhold Publishing Corporation, New York, p. 344.

[16] Michell RH (2007) Evolution of the diverse biological roles of inositols. Biochem Soc Symp. 74: 223-246.

[17] Shen X, Xiao H, Ranallo R, Wu WH, Wu C (2003) Modulation of ATP-dependent chromatin-remodeling complexes by inositol polyphosphates. Science 299: 112-114.

[18] Rapiejko PJ, Northup JK, Evans T, Brown JE, Malbon CC (1986) G proteins of fat cells role in hormonal regulation of intracellular inositol 1,4,5-trisphosphate. Biochem. J. 240: 3540.

[19] Larner J (2002) D-chiro-inositol -iIts functional role in insulin action and its deficit in insulin resistance. Int. J. Exp. Diabetes Res.3:47-60.

[20] Kumar YL, Nadh RV, Radhakrisinami PS (2012) Kinetics of oxidation of myo-inositol by potassium periodate in alkaline medium. Asian J. Chem. 24:5869-5872.

[21] Nayak GT, Hadmani CC, Harihar AL (2015) Kinetic and mechanistic investigations of oxidation of myo-inositol by diperiodatocuprate(III) in aqueous alkaline medium. Chem. Sci. Trans. 4:199-207.
[22] Nayak GT, Hadmani CC, Harihar AL (2014) Oxidation of myo-inositol by alkaline permanganate and the effect of alkali metal ion catalysts: kinetic and mechanistic approach. Know Res. 1:33-39.

[23] Kumar A, Rain M (1974) Mechanism of oxidation of cyclohexanehexol (inositol) by quinquevalent vanadium (pages). Int J ChemKinet. 6:15-28.

[24] Santoro M, Caffaratti E, Salas-Peregrin GM, Korecz L, Rockenbauer A, Sala LF, Signorella F (2007) Kinetics and mechanism of the chromic oxidation of myo-inositol. Polyhedron 26:169-177.

[25] Vogel IAA (1978) Text Book of Quantitative Inorganic Analysis. $4^{\text {th }}$ Ed. ELBS and Longman, New York, p. 352.

[26] Furniss BS, Hannaford AJ, Smith WG, Tatchell AR (2004) In Vogel's textbook of practical organic chemistry, $5^{\text {th }}$ (ed.) (Pearson Education Ltd).

[27] Vogel AI (1973) In Text book of practical organic chemistry, $3^{\text {rd }}$ (ed.) (London: Longman) p. 332.

[28] Feigl F (1975) Spot tests in organic analysis, p. 195, Elsevier, New York.

[29] Bailey N, Carrington A, Lott T, Symons MCRJ (1960) Structure and reactivity of the oxyanions of transition metals. Part VIII. Acidities and spectra of protonated oxyanions. J. Chem. Soc. 290-297.

[30] Carrington A, Symons MCRJ (1963) Structure and reactivity of the oxyanions of transition metals. Chem. Rev. 63:443-460

[31] Michaelis L, Menten ML (1913) The kinetics of invertase action. Biochem. Z., 49: 333-369.

[32] Amis ES (1966) Solvent effect on reaction rates and mechanism, p. 28, Academic Press, New York.

[33] Frost AA, Person RG (1973) Kinetics and mechanism, p. 147, Wiley Eastern, New Delhi.

[34] Weissberger A (1974) In Investigation of rates and mechanism of reactions in techniques of chemistry, (New York: John Wiley \& Sons), p. 421. 